\title{
PROFILE OF STILLBIRTHS IN A REFERRAL HOSPITAL FROM NORTHEAST INDIA- A RECORD BASED STUDY
}

\author{
Jenita Baruah', Giriraj Kusre2, Siddharth Hazarika ${ }^{3}$ \\ ${ }^{1}$ Associate Professor, Department of Community Medicine, Assam Medical College, Dibrugarh. \\ ${ }^{2}$ Associate Professor, Department of Anatomy, Assam Medical College, Dibrugarh. \\ 3 Junior Resident, Department of Anatomy, Assam Medical College, Dibrugarh.
}

\section{ABSTRACT}

\section{BACKGROUND}

A foetal death is defined as "death prior to the complete expulsion or extraction from its mother of a product of conception, irrespective of the duration of pregnancy; the death is indicated by the fact that after such separation the foetus does not breathe or show any other evidence of life, such as beating of the heart, pulsation of the umbilical cord, or definite movement of voluntary muscles" without specification of the duration of pregnancy. India has highest number of stillbirths in the world. Stillbirths are largely preventable if good quality obstetric care is made available at the right time. Currently, there are no global, systematic estimates for stillbirth causes of death. Acquiring more knowledge about stillbirths is important because of its significant contribution to adverse pregnancy outcomes.

Aim- The purpose of the study is to understand the stillbirth profile to understand sociodemographic profile of the affected mothers, aetiology and seek ways of avoiding its recurrence by identification of risk factors.

\section{MATERIALS AND METHODS}

The study is a record based retrospective carried out in a tertiary care hospital from northeast India, from January 2016 to June 2016. Records were examined for address of the mother, her age, gestational age, gravida and parity, medical and obstetrical condition leading to stillbirth, weight, sex and condition of the foetus at the time of birth (macerated or fresh).

\section{RESULTS}

Total 4078 numbers of live births were recorded during the period of study. Total number of stillbirths recorded in the stillbirth registry was 114. Stillbirth rate for the hospital was 27.95/1000 births. Most of the mothers experiencing stillbirth were of the age group 20-25 years (52.6\%) and were multiparous. Preterm was the most common gestational age group among stillbirths. Pregnancy-induced hypertension was the most common cause of stillbirth.

\section{CONCLUSION}

Present study shows that the risk of stillbirth is more among multigravidae women of age group of 20-25 years with prematurity and pregnancy-induced hypertension being other risk factors. Better obstetrical care can help in reduction of stillbirth rate.

\section{KEYWORDS}

Stillbirth, Profile, Northeast India.

HOW TO CITE THIS ARTICLE: Baruah J, Kusre G, Hazarika S. Profile of stillbirths in a referral hospital from Northeast India- A record based study. J. Evolution Med. Dent. Sci. 2017;6(21):1683-1686, DOI: 10.14260/Jemds/2017/370

\section{BACKGROUND}

A foetal death is defined as "death prior to the complete expulsion or extraction from its mother of a product of conception, irrespective of the duration of pregnancy; the death is indicated by the fact that after such separation the foetus does not breathe or show any other evidence of life, such as beating of the heart, pulsation of the umbilical cord, or definite movement of voluntary muscles" without specification of the duration of pregnancy.[1] For international comparison, WHO defines a stillbirth as late foetal death with birth weight of $1000 \mathrm{~g}$ or more or gestational age of 28

Financial or Other, Competing Interest: None.

Submission 05-02-2017, Peer Review 05-03-2017,

Acceptance 07-03-2017, Published 13-03-2017.

Corresponding Author:

Dr. Giriraj Kusre,

Associate Professor,

Department of Anatomy,

Assam Medical College,

Dibrugarh-786002, Assam.

E-mail: giriraj_kusre@rediffmail.com

DOI: $10.14260 /$ jemds $/ 2017 / 370$

\section{(c) $(i)(-)$}

weeks or more.[2] India has highest number of stillbirths in the world - the rates range from 20 to 66 per 1000 births in different states. Stillbirths usually have obstetric causes and largely preventable if good quality obstetric care is made available at the right time.[3] Government of India has planned to reduce the Stillbirth Rate (SBR) to $<10$ by 2030, and to achieve this target, it has given priority to establish a sound surveillance system for tracking stillbirths. [4] Currently, there are no global, systematic estimates for stillbirth causes of death. Where data do exist, the lack of comparability across studies greatly inhibits interpretation.[1] Most studies of stillbirth in developing countries have not included the birth weight, an important proxy for viability, especially where reliable gestational age dating is unavailable. Often data of stillbirths are not recorded and if recorded there is often missing vital information on weight of the stillbirth, sex, gestational age, and cause of death.[5] Acquiring more knowledge about stillbirths is important because of its significant contribution to adverse pregnancy outcomes.[6] The purpose of the study is to understand the stillbirth profile to understand sociodemographic profile of the affected mothers, aetiology and seek ways of avoiding its recurrence by identification of risk factors. 


\section{MATERIALS AND METHODS}

The study was a retrospective record based study, carried out in a tertiary care hospital from northeast India, from January 2016 to June 2016. Stillbirth was defined as the late foetal death occurring after 28th week of gestation and weighing more than 1000 g. Ethical clearance was taken from the institutional ethical committee prior to the initiation of the study. All case sheets of the women who had experienced stillbirth were retrieved from the department of medical records with the due permission from the Medical Records Department and were examined for detailed information regarding address of the mother, her age, gestational age, gravida and parity, medical and obstetrical condition leading to stillbirth, weight, sex and condition of the foetus at the time of birth (macerated or fresh). Relevant data was noted. Stillbirth rate was calculated by dividing the numbers of stillbirths during the period by total numbers of live births multiplied by 1000 . Descriptive analysis was conducted to present the results.

\section{RESULTS}

Total 4078 numbers of live births were recorded during the period of study. Total number of Stillbirths recorded in the stillbirth registry was 114 . Stillbirth rate for the hospital was 27.95/1000 births. Most of the mothers experiencing stillbirth were of the age group 20-25 years (52.6\%) and were multiparous [Table 1] with preterm being the most common gestational age group. Pregnancy-induced hypertension (26.2\%), severe anaemia (21.9\%) and $\mathrm{APH}$ (13.1\%) [Table 2] were the most common associated risk factors.

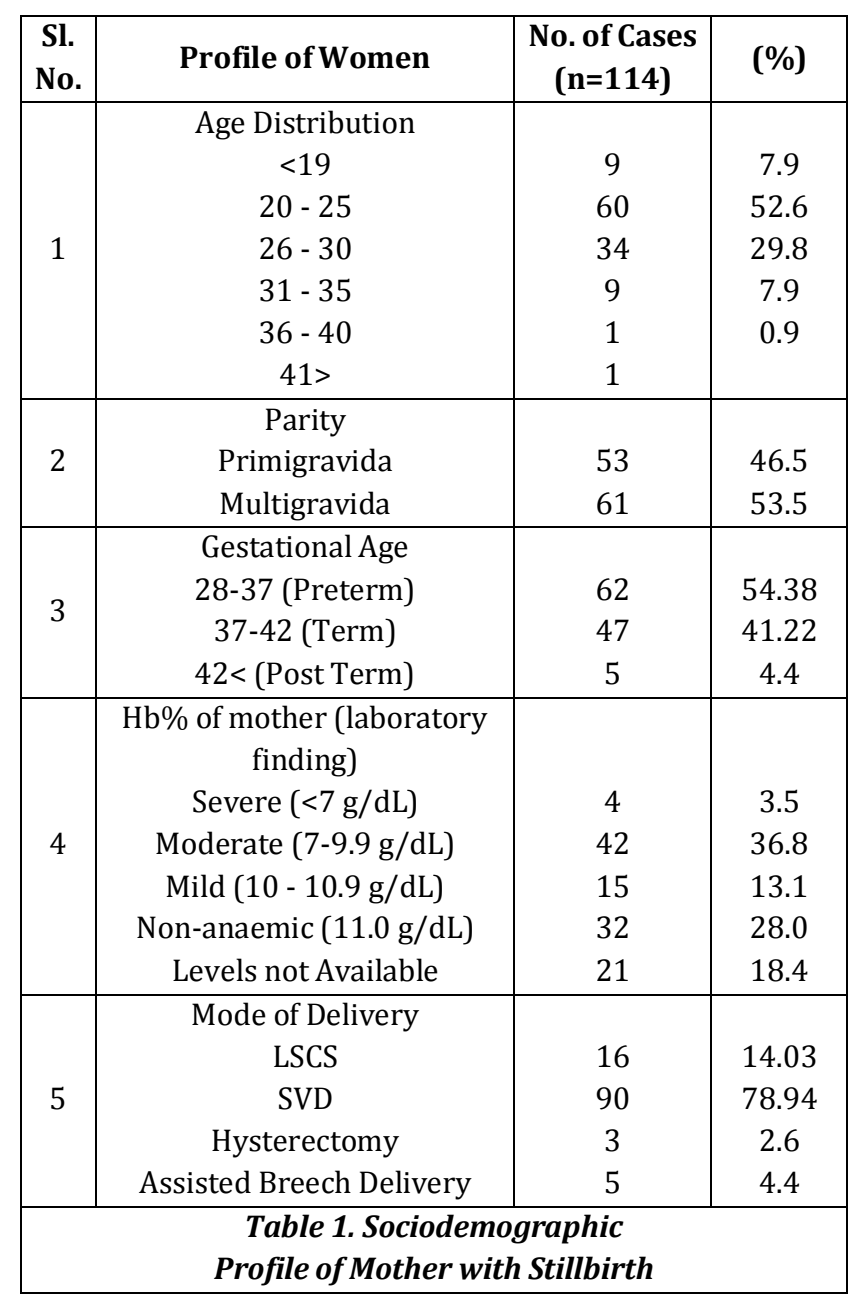

\begin{tabular}{|c|c|c|c|}
\hline $\begin{array}{c}\text { Sl. } \\
\text { No. }\end{array}$ & Etiology & $\begin{array}{l}\text { No. of } \\
\text { Cases }\end{array}$ & $\begin{array}{c}\text { Percen- } \\
\text { tage } \\
\text { (Out of } \\
\text { Total } \\
\text { Cases) }\end{array}$ \\
\hline 1 & $\begin{array}{c}\text { Maternal Medical Condition }(\mathrm{n}=60) \\
\text { Anaemia (Clinically) } \\
\text { Maternal Hypertension } \\
\text { Diabetes } \\
\text { Cirrhosis } \\
\text { Hypothyroidism } \\
\text { Nephritic Syndrome } \\
\end{array}$ & $\begin{array}{c}25 \\
30 \\
2 \\
1 \\
1 \\
1\end{array}$ & $\begin{array}{c}21.9 \\
26.2 \\
1.8 \\
0.87 \\
0.87 \\
0.87 \\
\end{array}$ \\
\hline 2 & $\begin{array}{c}\text { Obstetrical Condition }(\mathrm{n}=36) \\
\text { APH } \\
\text { Birth defect } \\
\text { Post CS } \\
\text { PROM } \\
\text { Transverse Lie } \\
\text { Rupture of Uterus } \\
\text { Cord Prolapse } \\
\text { Cephalopelvic Disproportion } \\
\text { Face Presentation } \\
\text { Uterovaginal Prolapse }\end{array}$ & $\begin{array}{l}15 \\
4 \\
4 \\
3 \\
3 \\
2 \\
2 \\
1 \\
1 \\
1\end{array}$ & $\begin{array}{l}13.1 \\
3.5 \\
3.5 \\
2.6 \\
2.6 \\
1.8 \\
1.8 \\
0.87 \\
0.87 \\
0.87\end{array}$ \\
\hline 4 & Medical + Obstetrical Condition & 12 & 10.5 \\
\hline 3 & Cause Unknown & 30 & 25.43 \\
\hline
\end{tabular}

\section{DISCUSSION}

Worldwide in 2015, for every 1000 total births, 18.4 babies were stillborn, mostly in low- and middle-income countries.[6] Stillbirth rates are usually high in developing countries representing $98 \%$ of estimated stillbirths occurring annually worldwide, while rates in developed countries are as low as 3 -5 per thousand births. Lack of access to obstetrical care at delivery, various socio-demographic factors, lack of education and poor nutrition are common cause of high rate of stillbirths in developing countries.[7] Stillbirth rates differ over different geographical region as there is no uniformity in defining stillbirth and differences in other regional factors. ${ }^{[8]}$ Authors from different parts of India have reported stillbirth rates as 33.3/1000 from Ahmednagar,[9] 36.0/1000 from Punjab,[10] 40.0/1000 from rural area in western India,[11] 49.0/1000 from Uttarakhand[12] and 57.9 per 1000 births from Karnataka.[13] Stillbirth rate for the present study was 27.95 per 1000 births. The difference between observations of different authors was probably due to difference in definition of stillbirth or due to regional difference.

In the present study, $52.6 \%$ of the mothers who had experienced stillbirth were of the age group of 20-25 years, this observation was similar to the observations from North Bengal,[14] rural hospital in Western India,[11] Uttarakhand,[12] and Karnataka.[13] Shubhada Sunil Avachat[11] observed no significant association with this age group and the high rate of Stillbirth among this group to be due to high fertility rate.

Studies from various parts of India has shown that the risk of stillbirth differs among primi and multigravidae women. Studies from Karnataka (48.2\%),[13] and Uttarakhand $(44.6 \%)^{[12]}$ had less stillbirths among primigravidae whereas rural western Maharashtra (56\%),[9] and North Bengal $(56.72 \%)^{[14]}$ had more numbers of stillbirths among the same group. Present study had lower (46.5\%) risk of stillbirth among primigravidae women. According to Cande V Ananth, the gravidity effect may be partly because of the association 
between higher number of pregnancies and low socioeconomic status.[15]

Prematurity was observed to be a factor associated with stillbirths in studies from India. Contrary to more numbers of premature stillbirths observed in rural hospital of Maharashtra (78\%),[9] Uttarakhand (60.95\%),[12] Karnataka $(56.30 \%)^{[13]}$ the studies from North Bengal $(47.26 \%)^{[14]}$ and Punjab $47.2 \%\left[{ }^{[10]}\right.$ had less numbers of premature stillbirths. In the present study, $54.38 \%$ of stillbirths were premature. Severe preeclampsia, placental abruption, uterine rupture, cholestasis, foetal distress and foetal growth restriction are some of the common causes of preterm birth.[16] The high number of stillbirths born prematurely is probably due to common aetiological factors.

In the present study, pregnancy-induced hypertension was the most common cause of stillbirth (26.2\%), followed by unknown cause $(25.43 \%)$ and abruptio placentae $(13.1 \%)$. According to Karen Wou et al 2014,[17] most common cause of stillbirth is unknown, followed by abruptio placentae and pregnancy-induced hypertension. In Nigeria, most common cause of stillbirth was unknown followed by abruptio placentae (17.7\%) and PIH (12.7\%).[18] In a 10-year cohort study in Portugal, about $1 / 4^{\text {th }}$ of stillbirths were due to cause unknown.[19] In Iran, most common cause of stillbirth was isolated hypertension (19.6\%) with just $2.8 \%$ of cases of stillbirth occurring due to abruption placentae.[20] Hypertensive disorders of pregnancy was the best known cause of foetal death in western countries.[21] In the present study, maternal hypertensive disorders was the major contributor for stillbirth exceeding the death due to unknown cause, reason for which needs to be investigated.

In the present study, about $21.9 \%$ women who experienced stillbirths had anaemia diagnosed clinically. In about $18.4 \%$ of mothers, records of haemoglobin percentage was missing, hence the true picture of nutritional status of the mothers was not expressed in the records. Various studies have shown inconsistent association between anaemia and stillbirth. In a prospective study in Bengaluru, anaemia among pregnant women had 1.8 times increased risk of foetal death compared to the non-anaemic population. ${ }^{[22]}$ In studies from Punjab (74.4\%) ${ }^{[10]}$ and rural Maharashtra (60.13\%),[11] high number of stillbirths were born to mothers having anaemia. Nutritional anaemia was the most common associated condition of stillbirth in Karnataka.[13] A population based case control study in Iran, observed that decreased haemoglobin concentration, as measured during pregnancy or the second trimester were associated with reduced stillbirth risk.[23] Introduction of various nutritional strategies specifically aimed at reducing a common cause of stillbirth, by supplementation of minerals have generally been ineffective. ${ }^{[8]}$ Further research is needed to identify the role of anaemia as a risk factor for stillbirths.

In the present study, about $78.94 \%$ of stillbirths were born by spontaneous vaginal delivery followed by delivery by caesarean section. In hospital based studies from North Bengal[14] and Nigeria, ${ }^{[18]}$ it was observed that the percentage of stillbirth was more among vaginal delivery in comparison to delivery by caesarean section. Women who lack skilled care at delivery and who do not have access to emergency obstetrical care are among those at greater risk for stillbirth. Timely delivery, and availability of cesarean section, can reduce stillbirth associated with prolonged and obstructed labour and associated asphyxia, preeclampsia/eclampsia. Delivery by a skilled birth attendant specially in a community does not mean the availability of caesarean section as emergency obstetrics care, as even a skilled birth attendant may not be an expert in conducting caesarean section. ${ }^{[8]}$ In most of the cases of antepartum stillbirths, operative procedure is avoided due to negative obstetric outcome except in condition such as transverse lie, or eclampsia etc, resulting in more numbers of stillbirths contributed to vaginal delivery. So, risk of stillbirth associated with that of spontaneous vaginal delivery may not represent the true picture.

\section{CONCLUSION}

Present study shows that the risk of stillbirth is more among multigravidae women of age group of 20-25 years. Prematurity, pregnancy-induced hypertension and abruptio placentae were observed to be the most common aetiological factors associated with stillbirth, hence better obstetrical care can help in reduction of stillbirth rate.

\section{Limitation}

This was a hospital based study, hence is not representative of the community. As the anaemia mentioned in the records of the mothers was based on clinical evaluation there may exist a difference of perception between obstetricians. The records of haemoglobin level of the mothers, which represent true picture of their nutritional status, was missing in about $18.4 \%$ of cases, hence the haemoglobin level discussed does not represent the nutritional status of the mothers.

\section{ACKNOWLEDGMENTS}

We acknowledge the contribution of Medical Record Department (MRD) who has agreed to share the records of the mothers.

\section{REFERENCES}

[1] Lawn JE, Gravett MG, Nunes TM, et al. Global report on preterm birth and stillbirth (1 of 7): definitions, description of the burden and opportunities to improve data. BMC Pregnancy and Childbirth 2010;10(Suppl 1):S1.

[2] WHO. International classification of diseases $10^{\text {th }}$ revision (ICD-10). http://www.who.int/classifi cations/ icd/en/ (accessed Aug 20, 2016).

[3] Bhati DK. Stillbirths: a high magnitude public health issue in India. South East Asia Journal of Public Health 2013;3(1):3-9.

[4] INAP (India New Born Action Plan). Ministry of health and family welfare, government of India. 2014 Available at http://nrhm.gov.in/images/pdf/ programmes/inap-final.pdf.

[5] Kusre G, Baruah J. Missing stillbirth data: a hospital based study. Int J Community Med Public Health 2016;3(10):2949-52.

[6] Mcclure EM, Wright LL, Goldenberg RL, et al. The global network: a prospective study of stillbirths in developing countries. Am J Obstet Gynecol 2007;197(3):247.e1-5. 
[7] Blencowe $\mathrm{H}$, Cousens S, Jassir FB, et al. National, regional, and worldwide estimates of stillbirth rates in 2015, with trends from 2000: a systematic analysis. Lancet Glob Health 2016;4(2):e98-108.

[8] McClure EM, Goldenberg RL. Stillbirth in developing countries: a review of causes, risk factors and prevention strategies. J Matern Fetal Neonatal Med 2009;22(3):183-90.

[9] Vidyadhar BB, Rajiv CM, Hrishikesh PA. Review of socio demographic factors and obstetric causes of stillbirths at tertiary care hospital. IOSR Journal of Pharmacy 2012;2(3):475-8.

[10] Sharma S, Sidhu H, Kaur S. Analytical study of intrauterine fetal death cases and associated maternal conditions. International Journal of Applied and Basic Medical Research 2016;6(1):11-3.

[11] Avachat SS, Phalke DB, Phalke VD. Risk factors associated with stillbirths in the rural area of Western Maharashtra, India. Archives of Medicine and Health Sciences 2015;3(1):56-9.

[12] Choudhary A, Gupta V. Epidemiology of intrauterine fetal deaths: a study in tertiary referral centre in Uttarakhand. IOSR Journal of Dental and Medical Sciences 2014;13(3):3-6.

[13] Prasanna N, Mahadevappa K, Antaratani RC, et al. Cause of death and associated conditions of stillbirths. Int J Reprod Contracept Obstet Gynecol 2015;4(6).

[14] Bhattacharya S, Mukhopadhyay G, Mistry PK, et al. Stillbirth in a tertiary care referral hospital in North Bengal- a review of causes, risk factors and prevention strategies. Online J Health Allied Scs 2010;9(4):4.

[15] Ananth CV, Liu S, Kinzler WL, et al. Stillbirths in the United States, 1981-2000: an age, period, and cohort analysis. Am J Public Health 2005;95(12):2213-7.
[16] Blencowe H, Cousens S, Chou D, et al. Born too soon: the global epidemiology of 15 million preterm births. Reproductive Health 2013;10(Suppl 1):S2.

[17] Wou K, Marie-Pier O, Moy-Fong C, et al. Comparison of the aetiology of stillbirth over five decades in a single centre: a retrospective study. BMJ Open 2014;4(6):e004635.

[18] Mutihir JT, Eka PO. Stillbirths at the Jos university teaching hospital: incidence, risk, and etiological factors. Nigerian Journal of Clinical Practice 2011;14(1):14-8.

[19] Robalo R, Pedroso C, Amaral N, et al. Late stillbirth: a ten year cohort study. Acta Med Port 2013;26(1):3942.

[20] Mohamadzadeh A, Daneshpasand G, Farhat ASH, et al. Prevalence and etiology of stillbirth in three university hospitals in Mashhad. Iranian Journal of Neonatology 2012;3:8-9.

[21] Reddy UM, Goldenberg R, Silver R, et al. Stillbirth classification--developing an international consensus for research: executive summary of a national institute of child health and human development workshop. Obstet Gynecol 2009;114(4):901-14.

[22] Sangeeta VB, Pushpalatha S. Severe maternal anemia and neonatal outcome. Sch J App Med Sci 2014;2(1C):303-9.

[23] Maghsoudlou S, Cnattingius S, Stephansson 0, et al. Maternal haemoglobin concentrations before and during pregnancy and stillbirth risk: a populationbased case-control study. BMC Pregnancy and Childbirth 2016;16:135. 